\title{
COVID-19 Global health crisis
}

On a day sure to go down in history, March 11, 2020 when The World Health Organization announced COVID- 19 (SARS-CoV2) as a global pandemic. The first pandemic caused by a corona virus that changed our lives forever. ${ }^{1}$

It ignited the entire scientific community and health care systems around the globe. All were anxious to gather information about the virus in aid of public awareness.

Age remains the biggest determinant of mortality from COVID-19 as well as those with underlying medical conditions.

In Saudi Arabia, the COVID-19 crisis has been managed with prompt actions, as it is the custodian of Islam's holiest sites, responsible every year for the well-being of millions of pilgrims from countries around the world. Access to the two holy cities was barred as early as 26th of February, before a single COVID-19 case was reported in the Kingdom of Saudi Arabia, and even before the World Health Organization (WHO) had labelled COVID-19 as a global pandemic. This foresight helped achieve better outcomes in managing the virus spread.

Saudi Arabia's success story in managing the COVID-19 outbreak marks its outstanding agility in responding to public health emergencies, as well as ensuring the well-being of residents and pilgrims; a key pillar of the kingdom's healthcare strategy. According to UpToDate, ${ }^{2}$ the reported cases are: 359,549 cases which had an outcome, 353,353 (98\%) recovered/discharged, $6,196(2 \%)$ deaths, much lower than many places in the world. The WHO is partners with scientists and pharmaceutical companies all over the world racing to develop and deploy safe and effective vaccines. Luckily, a safe and effective vaccine has been found, which will facilitate the equitable access and distribution of vaccines globally. The COVID-19 vaccine center was launched at different regions in Saudi Arabia. The Ministry of Health advised Saudis and expats to register via the Sehhaty app to take the free vaccine, in pursuit of its excellent management of this pandemic and optimizing health care for everybody in Saudi Arabia whether citizen or resident.

There was a considerable rise of submission of Covid-19 articles from Opinion pieces, observational studies and clinical studies. As rapid dissemination of information is of paramount importance, publishers were pressured to making the information available timely while keeping their editorial requirements on point.

Several tools, datasets, curated hubs, preprint servers, dedicated portals for Covid-19 articles were made openly available. It has become clearer that open access to information is very important in this time of crisis.

The Saudi Medical Journal has long adopted an open access policy as it goes well with our mission to disseminate accessible, useful, up-to-date medical information to healthcare professionals of various specialties across the globe. Also, we at Saudi Medical Journal encourage availability of material on preprint servers.

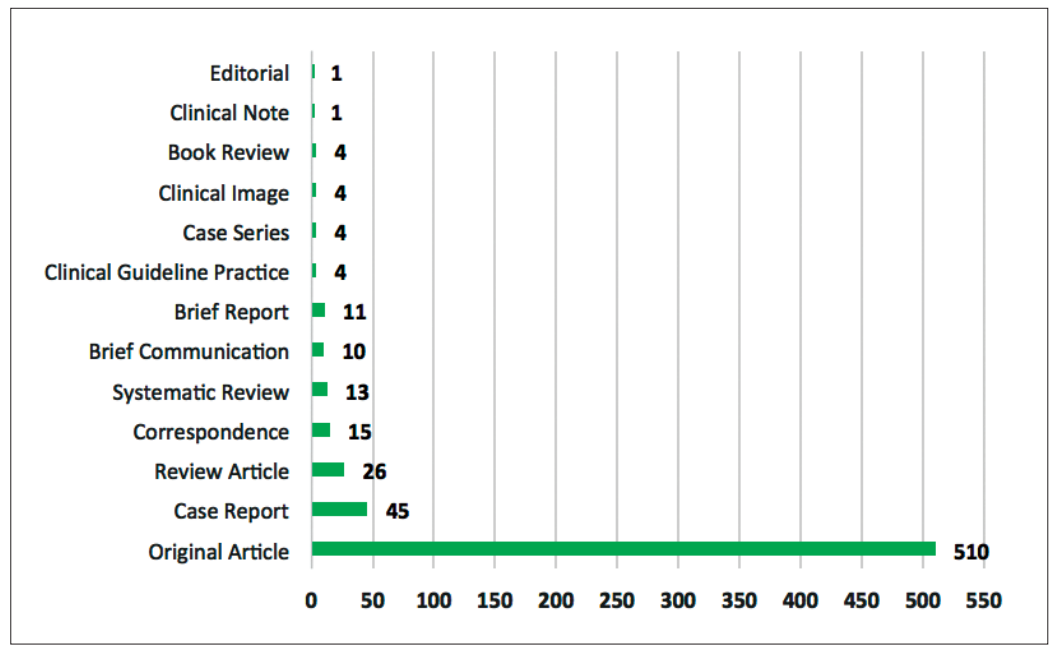

Figure 1 - Type of manuscripts received for the year 2020. 
Table 1 - Origin of "peer-reviewed" articles published in the Saudi Medical Journal for the year 2020 .

\begin{tabular}{lrr}
\hline Origin & $\mathbf{n}$ & $(\%)$ \\
\hline Kingdom of Saudi Arabia & 161 & $(83.4)$ \\
UAE & 3 & $(1.6)$ \\
Bahrain & 1 & $(0.5)$ \\
Egypt & 4 & $(2.1)$ \\
Lebanon & 1 & $(0.5)$ \\
Pakistan & 1 & $(0.5)$ \\
Turkey & 10 & $(5.2)$ \\
Australia & 1 & $(0.5)$ \\
UK & 3 & $(1.6)$ \\
China & 6 & $(3.1)$ \\
Japan & 1 & $(0.5)$ \\
USA & 1 & $(0.5)$ \\
Total & 193 & $(100.0)$ \\
\hline
\end{tabular}

The Saudi Medical Journal responded to this health crisis by publishing a Statement, Scoping Review, Systematic Reviews, Review Article, Original articles and Brief Communications. Some are available in the WHO Global Research Database and LitCovid-NCBINLM-NIH. ${ }^{3,4}$

Despite the surge of Covid-related submissions, Saudi Medical Journal followed the usual procedure of peer-review and revision process thus explained the low number of Covid-related publications.

This year we revise our editorial requirements for Case Reports to include maximum of 4 tables or figures only. Likewise the Brief Report material must include 15 References. These updates will be available in our Instructions to Author.

In these challenging times, there is still some good news to share and we are pleased to announce the opening of our brand new website. As part of our ongoing commitment to deliver excellence, we have partnered with HighWire a well recognized scholarly publishing platform to achieve the website that is geared towards our requirements.

Annual statistics. This year we received 648 manuscripts from which we processed 272 articles that have complied with the journal requirements (Figure 1). Over the past 12 issues, we have published 2 Editorials, 4 Systematic Reviews, and 120 Originals, with a total of 1379 pages. Eighty-four percent of the papers we
Table 2 - Average processing time frame of articles published in the Saudi Medical Journal for the year 2020 .

\begin{tabular}{cccc}
\hline Year & $\begin{array}{c}\text { Received to } \\
\text { Acceptance } \\
\text { (Months) }\end{array}$ & $\begin{array}{c}\text { Acceptance to } \\
\text { Publications } \\
\text { (Months) }\end{array}$ & $\begin{array}{c}\text { Received to } \\
\text { Publications } \\
\text { (Months) }\end{array}$ \\
\hline 2020 & 2.9 & 1.5 & 4.4 \\
\hline
\end{tabular}

published were from the Kingdom of Saudi Arabia (Table 1). Our total rejection rate was $70 \%$ of which $58 \%$ were rejected at the initial decision. The average processing time frame of original articles in the year 2020 from received date to acceptance was 2.9 months, from acceptance to publication 1.5 months, and from received to publication 4.4 months (Table 2). The journal's latest impact factor is 1.195 . We will continue to strive to improve in this area with the help of our authors.

To our board members and peer-reviewers who is working on the frontline and still managed to participate in the peer-review process of the journal, we greatly appreciate you.

On behalf of the editorial team, we give honor to the dedicated researchers and the whole scientific community. Again we would like to thank everyone and we sincerely wish for your safety!

\section{References}

1. World Health Organization. WHO Director-General's opening remarks at the media briefing on COVID-19 - 11 March 2020. [Updated 2020 March 11; Accessed 2020 December 14]. Available from: https://www.who.int/director-general/speeches/ detail/who-director-general-s-opening-remarks-at-the-mediabriefing-on-covid-19---11-march-2020

2. UpToDate. Coronavirus disease 2019 (COVID-19). [Update 2020]. Available from: https://www.uptodate. com/contents/search?search=covid $\% 2019 \% 20$ cases $\% 20$ AND\%20359,549\%20cases\&sp=0\&search Type=PLAIN_ TEXT\&source=USER_INPUT\&searchOffset=1 \&autoComp lete $=$ false \&language $=$ en $\& \max =10 \&$ index $=\&$ autoCompleteTe $\mathrm{rm}=$

3. World Health Organization. COVID-19 Global literature on coronavirus disease. [Updated 2020; Accessed 2020 December 14]. Available from: https://search.bvsalud.org/globalliterature-on-novel-coronavirus-2019-ncov/?output=\&lang=en $\&$ from $=\&$ sort $=\&$ format $=\&$ count $=\& \mathrm{fb}=\&$ page $=1 \&$ skfp $=\&$ ind ex $=\mathrm{tw} \& \mathrm{q}=\% 28 \mathrm{tw} \% 3 \mathrm{~A} \% 28 \mathrm{Saudi}+\mathrm{Med}+\mathrm{J} \% 29 \% 29$

4. LitCovid. Saudi. [Updated 2020; Accessed 2020 December 14]. Available from: https://www.ncbi.nlm.nih.gov/research/ coronavirus $/$ docsum?text $=$ Saudi $\% 20 \&$ filters $=$ countries . Saudi\%20Arabia\&filters=journal.Saudi\%20Med\%20 J\&sort $=$ score $\% 20$ desc $\&$ page $=1$

Fahdah Alokaily, $M D$
Editor-in-Chief 